\title{
Commentary on "The inner table calvarial bone graft harvest: a source of primary bone graft in the management of craniomaxillofacial skeletal injuries" by AK Singh, et al.
}

\author{
Ian Jackson
}

Received: 20 July 2010 /Accepted: 20 July 2010/Published online: 3 August 2010

(C) Springer-Verlag 2010

When I initially received this paper for the journal, I felt very upset that I had not thought of this idea. I have spent many hours removing full-thickness skull grafts, taking the outer table, placing the inner table back in again, and then filling up the resulting calvarial defect with Surgicel and bone dust. Even with this technique, which always had a little overcorrection, there were still surface irregularities on the skull. What the authors have done is to solve the problem in the very simplest of fashions, and I congratulate them.

I think that this is summed up in the American saying "keep it simple, stupid!" 